\title{
Institutional pluralism, two publics theory and performance reporting practices in Zambia's health sector
}

\section{Introduction}

Research on public sector accounting in emerging economies (EEs) located within Africa remains limited although beginning to grow in recent years (Hopper et al, 2016; Lassou and Hopper, 2016). The recent increase in research activity may be attributed to a number of factors including the desire by accounting scholars to understand the implications of accounting reforms advanced by donor institutions in these countries (van Helden and Uddin, 2016). However, literature is still lacking in terms of how accounting practices emerging from donor agencies are implemented and monitored in the midst of pluralistic institutional environments that characterise EEs. Such knowledge is critical to the accounting community in view of the increased presence of donor institutions in EEs. For instance, the World Health Organisation (2013) reports that donors contributed 20 - 40 percent of total health financing in more than 14 countries in Africa in 2010; with Zambia receiving an average of 42 percent from donor sources between 2003 and 2006 (Ministry of Health, 2009). Further, more than half of health outcome performance monitoring indicators in Zambia emerge from the imperatives of supranational institutions (Ministry of Health, 2011). Such situations point towards the need for appropriate accounting and reporting systems suitable for multiple donor institutions (Everett, 2012; Hopper et al, 2016; Hopper, 2017). This paper contributes towards the growth of accounting research in Africa outside the larger and more economically dynamic African nations (e.g. Ghana, Nigeria, and South Africa) where accounting knowledge is particularly lacking (Soobaroyen et al, 2016). The paper makes this contribution through studying accounting and performance reporting practices within Zambia's public health sector to understand the mechanisms that are designed and implemented to meet the diverse information needs of multiple stakeholders.

Public sector environments in many EEs are increasingly perceived as being institutionally pluralistic and fragmented, especially within the health sector (World Health Organisation, 2013; Yu, 2013; Wickramasinghe, 2015). A growing body of literature (e.g., Annisette, 2004; Uddin and Tsamenyi, 2005; Rahaman et al, 2007; Rahaman, et al, 2010; Jayasinghe and Wickramasinghe, 2011; van Helden and Uddin, 2016) indicates that accounting, financial and performance measurement practices in EEs are often shaped by the pressure arising from supranational institutions such as the World Bank (WB), International Monetary Fund (IMF), United Nations (UN) and the World Health Organisation (WHO). Such practices may include accrual accounting, performance based budgeting and financing, performance auditing and cost-based pricing of public services (van Helden and Ouda, 2016; van Helden and Uddin, 2016). However, it is not clear from existing literature how such requirements may or may not conform with local practices in many EE contexts where non-capitalist kingship relations dominate practices of management, budgeting and costing (Wickramasinghe and Hopper 2005). In view of variations in cultural and value systems, separate sets of accounting and performance reporting mechanisms and structures may be required locally. 
The extent to which accounting and performance reporting practices in EEs may be in harmony with the information needs of diverse stakeholders including donor institutions remains unexplored. Therefore, EEs offer suitable environments for undertaking research enquiring into how institutional pluralism may create contradictions on organisational practices such as accounting and performance reporting. While research on how donor power and influence reflect resource allocation processes in EEs is growing (e.g., Rahaman et al, 2010), there is still need to accumulate knowledge on how actors in such pluralistic institutional environments engage in discourses intended to balance the needs of diverse stakeholders in the course of accounting and performance reporting (van Helden and Ouda, 2016). This study contributes towards the above need through exploring the level of harmony between multiple reporting practices and associated administrative structures within Zambia's health sector.

The foregoing background raises two important research questions:

1. What accounting and performance reporting practices, mechanisms and administrative structures are drawn upon within the health sector to meet the information needs of different stakeholder groups?

2. How do these accounting and reporting practices, mechanisms and administrative structures influence practices at different levels of the health sector?

In order to explore these questions, the study draws on institutional pluralism (Modell, 2014) and Ekeh's (1975) post-colonial theory of 'two publics' (Goddard et al, 2016) to depict variations embedded within pluralistic environments that are typical of EEs including Zambia. The application of Ekeh's (1975) theory was deemed suitable due to the postcolonial and pluralistic nature of Zambia's public healthcare institutional environment. Engaging with the theory helped to bring to the fore not only the power and influence of supranational institutions versus government practices on accounting but also the response of less powerful individuals working within government structures (van Helden and Ouda, 2016; Hopper et al, 2016) who are also responsible implementing donor prescriptions of accounting and performance reporting.

While Goddard et al (2016) is the only known study to have drawn on Ekeh's (1975) theory to study accounting practices in an EE, their study focused on the attempt by local government actors to achieve legitimacy through isomorphism and loose coupling. The current study contributes differently by blending the theory with institutional pluralism to investigate how government actors endeavour to fulfil accounting and performance reporting expectations of diverse stakeholders within the health sector. Therefore, this study is an attempt at identifying and critiquing accounting tools, practices and structures which provide a picture of the behaviours of actors in which the values and interests of local actors interplay with donor values and demands (van Helden and Ouda, 2016). The rest of the paper proceeds as follows. The next section reviews literature on accounting and performance reporting in EEs. Section 3 presents the study's conceptual framework while research methods are discussed in section 4. Research findings are presented in section 5 and the paper closes with the discussion and concluding remarks. 


\section{Accounting and performance reporting practices in EE contexts}

The definition of 'emerging economy' remains largely elusive. However, the UN, WB and IMF all consider EEs in terms of countries characterised by low income to high income per capita (van Helden and Uddin, 2016). African countries as part of EEs offer a useful research field for studying multiple accounting and performance reporting practices due to the pluralistic nature of their institutional environments. Several studies conducted in these countries provide evidence of the significant influence of supranational institutions such as the UN, the WB, the IMF and the WHO. The influence of these institutions is particularly evidenced on accounting, financial management and performance measurement and management practices through their lending activities (Rahaman et al, 2004; Uddin and Tsamenyi, 2005; Rahaman et al, 2007; Hopper et al, 2009). These institutions have shaped politics and economic policies in EEs since colonial times. To date international aid institutions' prescriptions dominate accounting practices in EEs (Neu and Ocampo, 2007). Many public services in EEs depend on external funding and cannot ignore the institutional and administrative structures emerging from the providers of funding (Hopper et al, 2009). Funding and accounting agreements in such pluralistic environments often entail a restructuring in governance mechanisms and bring financial technologies that at times may not be conversant to EEs' practices but may reaffirm the expertise, legitimacy and dominance of external funding institutions (Goddard and Assad, 2006; Neu et al., 2006; Soobaroyen and Ntim, 2013).

A number of these external accounting and reporting repertoires that are based on New Public Management principles are usually deemed to be distant from the interests of local communities in EEs. Saravanamuthu (2004) further contends that some of these accounting practices cannot reconcile competing stakeholder needs in EEs since they emphasise economic necessities of global elites while neglecting social issues of local communities like environmental degradation. External practices of accounting and financial management emerging from supranational institutions have also been questioned since they appear to be implemented for purposes of elevating the interests of economic elites rather than for meeting the social needs of the economically vulnerable (Annisette, 2004; Hopper et al, 2016). In their study of the implementation of development accounting in a Sri Lankan village, Jayasinghe and Wickramasinghe (2011) evidenced the challenge of local actors in implementing the WB's prescription to alleviate poverty through their development policies. These external policies contradicted local politics and existing social values and practices. Due to this contradiction, rural poverty was reproduced instead of being alleviated through empowering the rural poor to participate in decision making. The study indicates that it may not be feasible to establish local accountability with accounting practices introduced through purely external mechanisms. There are other studies conducted in African countries confirming similar results where local actors were constrained and internationally driven practices did not fully produce desired outcomes (e.g., Rahaman et al, 2004; Neu et al, 2010; Iyoha and Oyerinde, 2010). Goddard et al (2016) equally report of challenges encountered by local government actors in the Tanzanian public sector where participants were subject to a conflict between the moralities of civic and primordial publics. 
While gaming and corruption were perceived by actors as appropriate responses within the civic public, accountability and a sense of moral responsibility appeared to be closely associated with the primordial public. These findings are consistent with Rahaman et al's (2010) study where complications arose in the course of implementing an accounting system for a globally-funded HIV/AIDS programme in Ghana where tensions arose between global control mechanisms and local autonomy in the use of the accounting system. The study highlights the fact that the existence of multiple institutional requirements in these contexts increased both the quantity and complexity of accounting requirements. The influence of supranational institutions has equally been reported in the Pacific Islands such as Fiji where, for instance, new accounting and managerial technologies were imposed from outside constituencies but accommodated by internal management actors (Lawrence et al., 2009; Sharma and Lawrence, 2005; 2009). In many instances, such external tools and practices were adopted by governments in EEs in a more symbolic than substantive manner for purposes of maintaining legitimacy with funding institutions (Goddard and Assad, 2006; Mimba et al, 2013; Soobaroyen and Ntim, 2013; van Helden and Uddin, 2016). Under such circumstances, the adoption and implementation of accounting reforms based on external rationales reproduced an alien hegemony that did not increase local autonomy, democracy and accountability (Hopper et al, 2016). Further, these accounting reforms together with their discourse and language may encourage governments in EEs to abandon their development agenda as they seek to legitimate themselves to supranational institutions (Hopper et al, 2009; Hopper, 2017). Consequently, such practices may result in dubious development benefits (Awio et al, 2007). External policies may also induce reforms that may be incompatible with indigenous cultures, local democracy and domestic politics (Rahaman et al., 1997).

In contrast to the above situations, some accounting mechanisms in EEs are reported to mediate between the development discourses of supranational institutions and the needs of local societies. For instance, Wickramasinghe's (2015) study suggests that cost accounting practices adopted in a Sri Lankan hospital acted as a mediating instrument through loosening the post-colonial bureaucratic budget confinements. This helped to create a social space for individuals to consider cost-saving experiments in order to address wider policy concerns about hospital resource management. As expanded below, other studies have recently suggested the need for identifying and developing collective accounting and reporting mechanisms that fulfil the needs of diverse stakeholders. For instance, Jayasinghe and Uddin (2010) have pointed out that localisation-led development would require the wider participation and accountability through reporting to various stakeholders such as donors, the state and civil society (Everett, 2012; van Helden and Uddin, 2016). The approach places specific emphasis on the localisation of public services and the empowerment of local populations.

Policy discourses based on the notion of national participation and control as vehicles of development are seen to be favoured in recent times among supranational institutions such as the WB and IMF (Alawattage et al, 2015). The localisation of public services is considered to be a crucial element in the social development of local populations such as the enhancement of local stakeholder participation and eradicating racial, ethnic and gender discrimination. 
This configuration allows for a shift into different accounting and reporting structures and practices implemented in a collaborative manner such as participatory budgeting within locallevel institutions to fulfil downward accountability. Such arrangements are often seen as providing a more democratic, participative and social form of accountability. For instance, Awio and Northcott (2001) report of the participatory budgeting approach adopted by community-led HIV/AIDS initiatives in Uganda in which lower-level health sector managers were motivated to participate in budgeting processes. The arrangement is reported to have enhanced the productivity in their managerial roles (Awio et al, 2007; Hopper, 2017).

However, alternative evidence suggests that participatory budgeting practices were adopted and implemented elsewhere in a superficial and ceremonial manner (Uddin et al., 2011). Localised and participatory approaches are also reported to reproduce patronage politics and social inequalities (Jayasinghe and Uddin, 2010; Nyamori et al, 2012; Kuruppu et al, 2016). The foregoing review points towards the need to embrace accounting and performance reporting tools that are able to serve the needs and interests of multiple stakeholders operating in pluralistic environments that are characteristic of EEs. Such stakeholders may include politicians, managers, citizens and the consumers of public services (Nyamori et al, 2012; van Helden and Ouda, 2016). In addition to economic and political considerations, accounting and reporting tools and practices also need to meet the cultural values of important stakeholders (Ashraf and Uddin, 2013; Mimba et al, 2013). In this way, accounting systems may be able to effectively play a mediating role between development discourses of supranational institutions and local actors through participatory planning and implementation.

The reviewed studies suggest that donors may introduce their own reporting requirements for various reasons. While these practices strengthen the role and power of donor institutions, they are also questioned in relation to addressing local needs and developing local competencies. This paper is different from the reviewed studies since it focuses on national reporting practices compared to donor requests for reporting (financial accounting) and performance control (budgets, performance reports). In this way, the paper explores the compatibility and/or complementary nature of these reporting practices and how these influence accountability and governance practices within Zambia's health sector.

\section{Institutional pluralism and the theory of two publics}

This study draws on institutional pluralism and Ekeh's (1975) theory of two publics to inform a conceptual framework for analysing accounting and performance reporting practices within Zambia's public health sector. These two theories are discussed in detail below.

\subsection{Institutional pluralism}

Institutional theory (particularly neo-institutional sociology) has undergone a number of significant ontological and epistemological shifts in recent years. One such shift is the emergence of the concept of institutional pluralism (Modell, 2014). 
Institutional pluralism refers to situations where legitimacy-seeking actors are confronted by multiple institutional spheres with competing demands (Kraatz and Block, 2008; Yu, 2013). Contrary to institutionalisation processes in environments where a single institutional structure dominates and exerts isomorphic influences, a growing body of literature suggests that institutionalisation in pluralistic environments brings more challenges for organisational actors. Organisations operating in pluralistic environments are deemed to be multiply constituted since they have more than one institutionally ascribed identity and more than one societally sanctioned purpose (Kraatz, 2009).

In contrast to theoretical assumptions at the field level, studies at the organisational level have found that conflicts between organisational responses originating from the actions of actors and extant institutional structures to be of enduring nature (Burns and Scapens, 2000). This has been evidenced in sectors such as healthcare, education and other public services where organisations pursue multiple goals and where different professional and divergent interest groups work closely (Jarzabkowski et al, 2009; Yu, 2013). Therefore, such situations challenge actors to skilfully produce integrative practices out of contentious processes (Kraatz and Block, 2008; Kraatz, 2009; Pache and Santos, 2010; Yu, 2013). In such contexts, divergent interests may neither be reconcilable nor suppressed but they have to coexist. Attaining legitimacy to important stakeholders is a critical component in pluralistic environments as this has the capacity to affect access to resources and even organisational survival. Political approaches are often perceived as a suitable means through which integration may be achieved in organisations under multiple institutional pressures (Greenwood et al., 2011). Paralysis or even organisational failure are deemed as possible consequences particularly in situations where conflicting groups are equally powerful and where institutional logics influence perceptions about organisational goals (Pache and Santos, 2010; Yu, 2013).

Pluralistic environments are also able to create competition among groups that pay allegiance to different institutional logics and values (Marquis and Lounsbury, 2007; Kraatz and Block, 2008; Greenwood et al, 2011). Institutional pluralism has implications on organisational legitimacy, governance and change (Yang and Modell, 2013). For instance, Kraatz (2009) considers that pluralistic institutional environments have the capacity of creating persistent internal tensions within an individual organisation. Due to competing logics and values embraced by the pluralistic organisation, individuals and groups within its boundaries may attach different identities and purposes upon it (Lounsbury, 2008; Sharma et al., 2010; Sharma et al., 2014). Such an organisation may end up becoming a divided entity in terms of multiple shifting objectives and values that are politically determined by the tension emerging from its rival constituencies. The multiplicity of attention associated with pluralistic environments may result in open conflict as different stakeholders seek to impose their interests upon the organisation (Dunn and Jones, 2010). These tensions are consistent with the dialectical nature of values and practices embraced within Ekeh's (1975) two publics discussed below. 


\subsection{The theory of two publics}

Ekeh's (1975) theory of two publics is based on the effects of colonialism on African affairs. The theory depicts a dualism which underpins the attitude of an African individual towards, and his relationship with, the post-colonial state on the one hand and with his primordial community on the other (Onuoha, 2014). The dialectical colonial effects are believed to have led to a unique configuration in modern post-colonial Africa - the existence of two publics within a sovereign state (Ekong, 1988). Ekeh (1975) refers to these two publics as the 'civic' and the 'primordial'. The civic public is said to consist of the Western state and its attached structures (armed forces, police, public service, executive, legislative and judicial arms of government) while the primordial public comprises families, rural communities, and ethnic and religious groupings (Onuoha, 2014; Egede, 2016). The entrance of colonial masters into Africa led to the questioning of existing primordial values and practices including beliefs and cultural values that needed to be changed (Ekeh, 1975; Goddard et al, 2016). This questioning is often regarded to be the work of colonial administrators drawn from the rising bourgeois class in Europe that in turn created the African bourgeois class out of the colonial experience (Ekeh, 1975).

As Hopper et al (2009) have noted, colonial politics divided people into white imperialists and local inhabitants. Accordingly, the African bourgeois has had to conform to the ideologies, values and beliefs of the European bourgeois as a way of legitimating itself for continued material and economic benefits. However, it is equally believed that this benevolence came at a cost to many African countries including a crisis in social identity and traditional ethos (Ekong, 1988) due to the parallel existence of the two publics. Ekeh (1975) contends that most educated Africans are citizens of the two publics in the same society. While the relationship of such individuals to the primordial public is perceived to be moral, that to the civic public is regarded as amoral (Lawuyi, 2012). Consequently individuals, especially those working in the public sector, are perceived as operating in both publics where they have to switch from a moral posture in the primordial public to an amoral posture in the civic public (Goddard et al, 2016). The parallel existence of the primordial and the civic publics comes with great implications of a dialectical nature. One of these is an established belief that ideas, values and practices of Western origin assume a higher social status than their primordial counterparts. Such a scenario creates tension in the value system of individuals and societies (Lawuyi, 2012).

In post-colonial Africa, this dialectical position has invariably filtered into government and governance systems. African governments, as recipients of Western ideas, tools, mechanisms, structures and benefits like donor funding and (good) governance practices have had to implement these civic public practices in the midst of a predominantly primordial public. As Ekeh $(1975,1994 a, 1994 b)$ has noted, the dialectics embedded between these two publics constitute the uniqueness of modern African societies and their politics (Osaghae, 2006; Afolayan, 2012). Accordingly, Mbembe (2001) contends that the post-colonial relationship is not primarily a relationship of resistance or of collaboration but can best be portrayed as a relationship where its subjects have to share the same public space. 
Despite Ekeh (1975) subscribing to two publics, Mbembe (2001, p. 104) suggests that postcolonial Africa is characterised by multiple public spaces rather than just two, 'each having its own logic yet liable to be entangled with other logics when operating in certain contexts'. It is argued that the theorisation of the two publics is unnecessarily rigid in terms of its dichotomous framing and ignores the dynamic and pluralistic political and social processes currently taking place in post-colonial African societies (Onuoha, 2014). In harmony with this observation, Afolayan (2012, p. 47) has pointed out that:

[The]...characteristic of the post-colony is its capacity to be 'chaotically pluralistic'. In its attempt to create a system of meaning that will make the discipline of the target population possible, state power in the post-colony ends up creating a multiplicity of public spaces resulting from the equal attempt by the people to make sense of their collective predicament...

As a result of these multiple public spaces that are often of a chaotic nature, the post-colonial government has to learn to bargain in the pluralistic environment. Managers in the postcolony also need to possess abilities to manage not just a single identity but several and be flexible enough to negotiate as and when necessary (Mbembe, 2001). It is believed that such actors equally have to splinter their identities and to represent themselves as always changing their persona. In view of the pluralistic institutional environment arising from these multiple public spaces, it may be argued that diverse accounting and performance reporting practices need to be embraced in public institutions within post-colonial African states as government institutions attempt to attend to the needs of diverse stakeholders (Egede, 2016). Notwithstanding the criticism against Ekeh's (1975) rigid theorisation of the two publics, Osaghae (2006) considers the thesis of two publics to be fundamentally relevant even today for understanding African societies. It may be argued from the foregoing that Ekeh's (1975) theory is appropriate for application in pluralistic environments where institutional actors within post-colonial African states need to represent the interests of different stakeholders as they seek to remain legitimate. The blending of institutional pluralism with the theory of two publics helped to analyse the on-going and evolving accounting and performance reporting practices based on individual and collective experiences of actors operating in different institutions affected by donor activities within Zambia's health sector.

\section{Research Method}

In order to enhance the reader's understanding of the research methodology explained below, the structure of Zambia's public healthcare system is presented next. In line with the study's conceptual framework, this structure depicts the pluralistic nature of Zambia's institutional environment within the health sector.

\subsection{Structure of Zambia's health sector}

The Ministry of Health $(\mathrm{MoH})$ headquarters, the executive body responsible for health policy formulation, coordination and the overall management of the health sector in the country, forms the apex of the healthcare system. The activities of the Ministry are monitored and overseen by the Parliamentary Committee on Health that only enjoys advisory powers. 
This Committee also plays an advocacy role to ensure that the country's health policy and the delivery of health services meet the health needs of ordinary citizens whom the Members of Parliament represent in the House. 'External' influential structures comprising donor institutions who contribute more than 42 percent towards the country's total health expenditure exist at this level (MoH and World Bank, 2010). Intermediate regional structures in form of Provincial Health Offices are responsible for providing a functional link between the Ministry headquarters and District Health Offices. Provincial Health Offices are also in charge of coordinating and supervising the implementation of health programmes within respective provinces. Intervening these structures are statutory bodies responsible for regulating health service delivery including the General Nursing Council of Zambia and the Health Professions Council of Zambia. District Health Offices are responsible for coordinating primary healthcare at the district level.

On the service delivery side, Zambia runs a five-tier health service delivery system that helps to focus on the healthcare needs of citizens at different echelons of society. Health posts and health centres are responsible for delivering primary healthcare at the community level. These facilities are located within low-income urban residential areas, peri-urban areas and village communities. Health posts and health centres are managed by neighbourhood health committees that facilitate the linkage between local communities and the civic healthcare system. District hospitals also provide primary healthcare but at the district level. The provision of secondary care at the provincial level is the mandate of general hospitals while tertiary care at the national level is provided by central hospitals and teaching hospitals. Out of a total of 1,882 health facilities in the country as at 2010,1,489 were run by government (79 percent) while 271 facilities (14 percent) were run by private institutions. The rest (7 percent) were run by donor-funded agencies that include Non-Governmental Organisations (NGOs) (MoH, 2011).

\subsection{Fieldwork}

This study adopted a qualitative methodological approach that is consistent with interpretive research (Vaivio, 2008). The research methodology was guided by the study's conceptual framework in terms of how institutional pluralism and the theory of two publics may produce diverse social values among different stakeholders regarding accounting and performance reporting practices. In line with the study's theoretical underpinning, the study sought to understand how actors involved in health service delivery construct their accounting and performance reporting mechanisms to meet the information needs of different stakeholders. Accordingly, the data collection process explored different accounting and reporting tools that reflected the needs of both government and donor institutions (Ekeh, 1975). As explained above, the healthcare delivery system caters for populations located at different points on the social strata ranging from village communities to urban set-ups. Empirical data was initially collected from archival evidence based on policy, planning, monitoring and review reports sourced from the $\mathrm{MoH}$ headquarters. These documents contain information describing Zambia's healthcare performance reporting and monitoring frameworks. 
Such official documents provided useful information regarding the general context of healthcare performance and past and ongoing practices on accounting and performance reporting. Primary data collection was effected using semi-structured interviews with 33 respondents drawn from the main stakeholder groups involved in health service delivery including legislators, policy makers, regulators, healthcare professionals and health service managers. Interviews helped to solicit the views of practitioners and decision makers in relation to reporting and control structures within the health sector and to comment on challenges of reporting regarding accounting and performance reporting practices. Out of the total sample of 33 respondents, there were 5 legislators, 6 policy makers, 7 regulators, 7 healthcare professionals and 8 health service managers. The logic behind this sampling approach was to speak to individuals who are involved in the design and implementation of health programmes, including those programmes that are funded by donor institutions. The multi-level sampling ensured that the views of individuals involved at strategy and policy levels through to service delivery at the facility level were included.

The selection of these respondents was based on their expertise with matters being investigated since they form part of the health service delivery system (Modell, 2003). Legislators were drawn from the Parliamentary Committee on Health that provides an oversight role on the activities of the $\mathrm{MoH}$ to ensure that policy formulation and implementation conforms to public expectations of health service delivery. Policy makers were drawn from the $\mathrm{MoH}$ headquarters. In addition to health policy formulation and implementation, policy makers are also responsible for mobilising, allocating and tracking resource utilisation. This stakeholder group has constant interactions with donor institutions and is usually the recipient of donor funding and prescriptions of accounting and performance reporting at the national level. On the other hand, healthcare professionals and managers are tasked with health service delivery and the implementation of donor practices at the facility level. These were drawn from various hospitals and clinics where access was provided to researchers. Regulators were drawn from the Health Professions Council of Zambia and the General Nursing Council of Zambia that monitor the performance of healthcare organisations to determine their compliance with healthcare standards in order to meet the health needs of the population.

Conducted between May and November 2013, interviews lasted an average of one hour per respondent. Interview questions focused on mechanisms and tools that individual and collective actors draw on in the course of accounting and performance reporting within the health sector. All interviews were conducted in English and recorded digitally. Data was later prepared by transcribing all audio recordings and reading through the transcripts several times to validate the content. Data analysis took the form of thematic analysis which involved identifying, analysing and constructing patterns and themes implicit within the data (Blumberg et al., 2011). The analysis was accomplished through coding the data based on recurring themes that reflected accounting and performance reporting practices intended for different audiences within the health sector. 
These themes represented chunks of text that captured important aspects about the data in relation to the research questions and represented some level of patterned response or meaning within the data (Tsamenyi et al., 2006; Sharma et al., 2010). Data analysis was conducted in light of the conceptual framework in order to compare and contrast experiences of different actors in their individual and collective perspectives of accounting and performance reporting practices that were deemed suitable for meeting the information needs of diverse communities. The analysis is presented below.

\section{Research Findings}

In line with the conceptual framework, the study's findings are presented based on the following identified categories: institutional pluralism in the health sector, accounting and performance reporting practices targeting civic audiences, accounting and performance reporting practices targeting primordial audiences, and collaborative accounting and reporting practices.

\subsection{Institutional pluralism in the health sector}

Zambia's health sector portrays features of institutional pluralism arising from the multiplicity of both internal and external stakeholders responsible for healthcare funding, health programme design, implementation and monitoring (Mbembe, 2001; Afolayan, 2012; Modell, 2014). Government has identified key stakeholder groups including the $\mathrm{MoH}$, the Churches Health Association of Zambia, civil society, and international donor institutions. In terms of funding modalities, the Ministry of Finance provides the budget for operating expenditures directly to the $\mathrm{MoH}$ while international donors provide the budget for health programme expenditures through basket funds to the $\mathrm{MoH}(\mathrm{MoH}, 2011)$. These basket funds are provided in tandem with government's budgetary allocation structures and are managed and monitored closely within the $\mathrm{MoH}$ expenditure framework. The $\mathrm{MoH}$ provides running costs (using government and basket funds) to health facilities and District Health Offices (MoH and World Bank, 2010).

International donor institutions are important stakeholders in Zambia, contributing an average of 42 per cent towards total health expenditure (MoH, 2009). However, donor funding is often not channelled through established government structures but goes directly to healthcare provider organisations identified by international donor agencies. In most cases, the allocation of such resources is done through NGOs and other contractors whom donors consider as their trusted agents for purposes of accountability and fulfilling their health service delivery priorities. Consequently, multiple reporting practices have emerged in order to attend to the information needs of different stakeholders. The Chairperson of the health committee relived his experiences on multiple reporting practices in the health sector while he served as a Cabinet Minister: 
There were instances where there would be multiple reporting systems by my staff. That was not the best utilisation of time in our country.

The parliamentarian further explained the tendency of international donor agencies in coming up with health programmes targeting areas not prioritised by government institutions. Consequently, such programmes led to multiple implementation approaches and accounting strategies and reporting practices.

Donors often say, 'We are accountable to our governments for these donor funds; here is how the programme should be done'...

Corroborating this account, a Medical Officer explained that due to the practice of bypassing government structures by international donor agencies and the subsequent multiplicity of health programmes, reporting practices had proliferated in recent years with the consequence of resource wastage due to poor performance monitoring. While the wastage has been observed in different areas, it has been evident under HIV/AIDS programmes.

There was so much duplication of programmes...That was the problem especially for [HIV]AIDS programmes.

Multiple accounting and reporting practices are equally evident within government structures where donor resources are received. For instance, donor resources provided through budgetary support are accounted for separately from resources provided through earmarked projects. The $\mathrm{MoH}$ is required to produce separate financial reports by different donor agencies based on their own reporting requirements. Saasa (2010, p.19) explains this point:

For the donors that fund the basket, the MoH produces a separate report biannually, which most basket funders have used to satisfy their own reporting requirements while in the case of some (such as USAID[United States Agency for International Development]), additional reports are produced by the Ministry.

These multiple reporting practices are deemed to be tailored towards meeting the needs of different stakeholders operating within the health sector. This institutional pluralism has implications on accounting and performance reporting practices in an attempt to meet the civic and primordial information needs of different stakeholders.

\subsection{Accounting and performance reporting practices in the pluralistic environment}

While acknowledging the problematic nature of Ekeh's (1975) dichotomous theorisation of the two publics, an analysis of the data reveals that three distinct formats of accounting and performance reporting are drawn upon by government actors to meet the information needs of diverse stakeholders. There are reporting practices that seem to target civic audiences while other practices are seemingly targeted at primordial audiences. Finally, collaborative structures and practices have emerged in recent years that attempt to harmonise accounting and performance reporting within the health sector. 


\subsubsection{Accounting and performance reporting practices targeting civic audiences}

Reporting practices targeting the civic public appear to focus on the provision of information primarily to meet the needs of international donor agencies and government civic institutions. Such macro reporting practices are intended to conform to the reporting expectations of global institutions including the UN and the WHO. The Deputy Director of Health Policy explained that such reporting practices focus on key performance indicators including mortality rates and immunisation coverage:

That is how we measure the performance of the health sector and it is a practice world over. We look at the identified key performance indicators, for example, maternal mortality, child mortality, immunisation coverage...because the UN, World Health Organisation want to see how the health sector is performing in Zambia.

It is interesting to note that the policy maker did not only consider performance indicators focusing on mortality rates and immunisation coverage as world practice but also acknowledged that this is the preferred format for reporting healthcare performance based on the demands of external civic institutions like the UN and the WHO (Annisette, 2004). This reporting practice is also consistent with the country's adopted performance monitoring framework that focuses on mortality rates and immunisation coverage as key healthcare outcome indicators $(\mathrm{MoH}, 2011)$. Consequently, donor agencies appear to prefer disease specific accounting and reporting practices that are based on their funding priorities. The Chairperson of the health committee who interacted closely with donor agencies reiterated the disease specific funding, accounting and reporting practices of these institutions.

Many times in developing countries these guys [donors] have come to say, 'We've got a pot of money for HIV and AIDS', the other one says, 'Malaria', and the other says, 'I'm concerned with diarrhoeal diseases so [here is] money for water and sanitation'.

With great reservations on such practices, a Principal Planner in charge of budgeting reiterated the disease specific funding and reporting approach embraced by external civic institutions. Such practices are deemed to fragment and compromise the effectiveness of health funding and monitoring.

Vertical funding or parallel funding: this is the situation where money is given through certain programmes - it could be earmarked for T.B., HIV/AIDS or malaria...That's not the way it should be...But there are certain partners [donors] who prefer to fund us like that due to their own reasons.

The pluralistic institutional environment and multiple accounting and reporting practices are perceived to emerge from donors' prioritisation of certain disease areas, particularly HIV/AIDS. Donor institutions embrace these funding and reporting practices despite perceptions by local stakeholders that such an approach tends to neglect other diseases prioritised by government. The Deputy Director of Monitoring and Evaluation explained:

There were projects specifically for HIV/AIDS until recently when we said, 'Look, we are not making as much progress as we might like by this isolation approach'. 
The perceived bias towards HIV/AIDS programmes and reporting is also acknowledged by the Chairperson who considers that non-communicable diseases have not received sufficient attention. While HIV/AIDS was considered as a national disaster that required concerted efforts in terms of funding and monitoring in order to stop its tragic spread and damage on the population, it is felt that an the isolated approach compromises the effectiveness of health service delivery.

So much damage was done because other diseases were not attractive. Money was in HIVIAIDS; leaving non-communicable diseases like cancer and hypertension...

The disease specific funding and reporting approach by donor institutions is acknowledged even by the government. For instance, a report by the $\mathrm{MoH}$ emphasises government's concern with fragmented donor funding practices as reflected by the National Health Accounts. The concern is not only due to donors' overemphasis on HIV/AIDS programmes but that donor resources are applied without the involvement of local stakeholders, leading to difficulties in performance evaluation of the health sector.

The majority of HIV/AIDS health funds averaging at 41 per cent were managed by donors and international NGOs...This situation raises the issue of the sustainability and effectiveness of aid for HIV/AIDS given the fact that little resources are under the control of the MoH...Unless resources are programmed in line with government priorities, the un-pooled donor resources may be used inefficiently making it difficult to monitor and evaluate its impact... (MoH 2009, p. xiv)

These accounts suggest that funding, accounting and performance reporting practices adopted by international donor institutions are primarily tailored towards meeting the information needs of external civic institutions especially donor agencies. These practices display little sympathy towards meeting the needs of local stakeholders within the primordial public. Practices suitable for these stakeholders are presented in section 5.3 below.

\subsubsection{Accounting and performance reporting practices targeting primordial audiences}

Oriented towards meeting the health needs of local families, the overarching aim of Zambia's health policy is:

To reduce the burden of disease, maternal and infant mortality and increase life expectancy through the provision of a continuum of quality cost effective healthcare services as close to the family as possible in a competent, clean and caring manner (MoH, 2013, p. 23).

While the above policy statement could have civic attachments, some reporting practices appear to be inclined towards bringing to the fore the information and health expectations of local stakeholders. In focusing on the needs of local communities, a policy maker reiterated that performance reporting needs to highlight people's living standards and improvements in healthcare performance. 
Accordingly, mortality rates have taken a central role as a key performance indicator of both healthcare performance and the living standards of local communities. A legislator explained:

When we talk about performance improvement, first and foremost we have to look at the objective of healthcare delivery. Basically we are trying to reduce mortality rates and we want to improve the general living standards of the people.

In corroborating this position, another legislator considers that healthcare performance reporting should reflect the fulfilment of citizen expectations of health. The lawmaker contended that in order for a government to be considered as performing, it must deliver health services according to the expectations of citizens who gave government the mandate to govern. Consequently, it is considered that healthcare performance reporting suitable for the primordial public should reflect the state of health facilities and the quality of services being provided.

Obviously what is important is that government is there to provide a service to its citizens...And what you expect is that once citizens elect a government they expect that there will be a hospital, a clinic, a health centre near where they live. And in that health centre - first of all it will be an appropriate building - that there will be medical staff, there will be support staff, there will be [quality] services, and that there will be drugs...

This account underscores the important legislative role of representation as it attempts to bring to the fore the interests of the primordial public whom legislators represent in Parliament. The account also reiterates government's overriding performance goal of providing citizens with quality services as close to the family as possible. The parliamentarian also emphasised that performance reporting should be based on government's vision as reflected in key development and health plans such as the Vision 2030. Accordingly, performance reporting within the primordial public is expected to reflect improvements in mortality rates, poverty levels and accessibility to health services through constructing more health facilities.

First of all there are national targets through the overall Vision 2030 where government's vision is that so many health centres should be built within every $5 \mathrm{~km}$ radius; we must reduce mortality rates by so much, we must reduce poverty by so much.

The legislator reiterated that government's key performance goal is that patients should not walk more than $5 \mathrm{~km}$ to access health services. This goal requires building health facilities for people living in the remotest parts of the country to ensure that health services reach communities located in rural settings. A Deputy Director of Health Policy stated that while civic institutions are interested in the performance of the sector at the national level, performance reporting within the primordial public needs to focus on facility level performance in order to reflect how local community health needs are being addressed by the health system. 
Consequently, performance reporting is expected to reflect how limited resources are utilised to meet the health needs of local communities, how promptly patients are attended to and how much time they spend in a health facility.

The picture I had given you earlier is a macro picture [for the civic public]...But where the health facility is concerned at the micro level, there are many things that we look at - how resources are utilised, the time spent [in the health facility], how long it takes for a patient to be seen by a practitioner...

In endorsing this position, a Chief Health Planner provided a more elaborate account of performance reporting within the primordial public. He clarified that while the ultimate goal in the civic public remains that of reducing morbidity and mortality rates, this is only attainable by putting measures in place to increase the coverage of health services at the health facility and community levels to reduce disease incidents:

In the health sector when we talk about performance, ultimately it is to reduce mortality. But before that we need to talk about disease incidents in terms of reducing the number of cases leading to death in malaria, for instance. If you are providing services, have you reached your targets? You said you will cover two million people with insecticide nets, have you done that?

Furthering this line of thought, a Monitoring and Evaluation Specialist explained that despite the main performance goal of reducing morbidity and mortality rates at the national level, the civic public goal can only be achieved through delivering quality health services to members of the primordial public in conformity with healthcare standards. These standards stipulate expectations in different areas of health service delivery including patient rights and responsibilities, human resource management, medical equipment availability, documentation of healthcare, etc. Accordingly, clinicians and nurses are expected to embrace the right attitude in the course of delivering care to local communities.

What we want to happen in any health facility is to ensure that the communities we are serving [should] receive the best care possible - quality care. What we want is to ensure that when we go to a health facility, we will find adequate numbers of staff; we will find equipment; we will need to see a nurse documenting the care that they are giving to the client. And we want the nurse to have a right attitude towards the patient.

In line with the above account, the Chairperson explained that his Committee carries out random oversight checks to validate performance improvement claims made by the Executive. This practice is intended to ensure that government does not only report information to suit the civic public but that such performance reporting equally reflects actual health improvement taking place within local communities.

The last session we enquired into maternal and child health. Why are we still having 519 mothers hang out of 100,000 deliveries? We were told that we had improved on maternal deaths from 729 to five hundred and something. 
So we said, 'Let's go and see for ourselves'. We saw with our own eyes that this is just on paper...The Ministry can say that we've done this but the Parliamentary Committee would want to verify that what they have been reporting is the reality on the ground...

Thus, despite certain performance reporting mechanisms being instituted for the civic public, the Parliamentary Committee ensures that these reporting practices are verified so that they also reflect the needs of local communities whom legislators represent in Parliament. These sections suggest that different reporting mechanisms and practices are drawn upon to suit the needs of different stakeholders resident in the civic and primordial public. As reported under section 5.2 however, contradictions have arisen between international donor institutions and government due to differences in funding and reporting priorities and practices within the health sector. In order to address these gaps, integrated and collaborative funding and reporting practices have emerged in the health sector as presented below.

\subsubsection{Collaborative accounting and reporting practices}

In addition to the dichotomous accounting and performance reporting practices presented in sections 5.2.1 and 5.2.2, collaborative reporting practices between government and donor institutions have emerged in recent years due to dynamics in the institutional environment (Onuoha, 2014). For instance, joint funding and reporting structures within the health sector have been instituted between government and donor institutions. Such structures involve committees that draw their members from government and donor institutions to ensure that the interests of diverse stakeholders are represented starting from programme funding, implementation, monitoring and reporting (Jayasinghe and Uddin, 2010; Wickramasinghe, 2015). This point was amplified by a Monitoring and Evaluation Specialist.

There are many activities that we do with technical and financial support from donors. So we produce quarterly reports and an evaluation is also done annually through the Joint Annual Programme Review. Then we have other evaluations such as mid-term reviews which involve the Joint Monitoring Mid-Term Review Process. And then we also have the end of project review where we look at the impact of what we have been doing as a country.

Further to the above account, policy literature indicates that the Joint Annual Review has been introduced within the health sector to assist in monitoring the performance of the health sector jointly between internal and external stakeholders. As such, it is intended to be a complimentary and harmonised measure for routine monitoring and evaluation of the performance of the health sector in order to promote transparency and accountability.

The Joint Annual Review (JAR) was introduced to assess the performance of Zambia's health sector on a yearly basis. The JAR complements existing routine monitoring and evaluation systems by providing the opportunity for a harmonised and jointly-planned annual assessment process. Its objective is to facilitate collaborative 
sector policy dialogue and review, with the ultimate aim of optimising informationsharing, transparency and mutual accountability (Republic of Zambia, 2013, p. i).

For instance, the 2012 JAR was undertaken with the main objectives of assessing and scoring progress of the health sector against key indicators that include benchmarks for delivery of district based services, reviewing key components of the District Annual Action Plans and activity based budgets in selected districts with a critical lens on maternal, neonatal and child health. The Review was also aimed at informing the annual planning process. The Joint Steering Committee is another structure that has emerged to promote integrated and coordinated reporting within the health sector between government and donor institutions. As Saasa (2010, p.16) reports,

The Joint Steering Committee (JSC) is part of the dialogue mechanism. It is composed of both government and donor representatives. The JSC's work is co-ordinated by the Joint Executive Committee (JEC) consisting of three representatives from GRZ [Government of the Republic of Zambia] and two donor members. The JEC handles coordination functions and prepares joint reviews...

Saasa (2010) further reports that dialogue on results and outcome indicators on poverty reduction and budget support is often undertaken through the Performance Assessment Framework (PAF). This dialogue mechanism enables government and donor institutions to assess the performance of the health sector in diverse areas including poverty reduction, financial management and social equity. Accordingly, this mechanism helps to bridge the reporting and information needs of both publics.

The PAF...includes a mixture of policy measures and results/outcome indicators. The donor-government dialogue revolves around the PAF particularly with respect to poverty reduction monitoring. The current PAF focuses mainly on four areas, namely, reform process, financial management, wealth creation, social equity...

Annual consultative meetings are equally held between government, donor institutions and NGOs to review the performance of the health sector in terms of its action plans and budget formulation and implementation.

Annual Consultative Meetings (ACMs)... are held each year. The purpose of the ACM includes the review of the previous year's MoH action plans and budgets; presentation and review of the MoH previous year's performance based on the annual reports; review of counterpart funds from MoH...Membership of the ACM includes officials from MoH, donors, statutory boards, line ministries, other government departments and NGOs (World Health Organisation, 2009, p. 16).

These joint approaches on reporting mechanisms are intended to harmonise funding and reporting practices between government and donor agencies. Such collaborative practices are equally meant to harmonise the information needs of members of the civic and primordial publics. 


\section{Discussion and concluding remarks}

Consistent with the theoretical framework, the foregoing findings indicate that Zambia's institutional environment within the health sector is highly fragmented and pluralistic. The pluralism is reflected by the multiplicity of both internal (usually local) and external (usually foreign) stakeholders. Among internal local stakeholders are groups including policy makers, parliamentarians, regulators and health service providers. As external stakeholders, international donor institutions include the UN, WHO, WB and other funding agencies such as the United States Agency for International Development and the Global Fund to fight Tuberculosis, AIDS and Malaria. These stakeholder groups need different reporting mechanisms to fulfil different stakeholder information expectations. For instance, the Chairperson of Parliamentary Committee has indicated how some donor groups insist on certain reporting mechanisms in order to fulfil accountability practices demanded by their home countries. However, a number of such reporting mechanisms are reported to be inconsistent with the requirements of government and other local stakeholders.

Ekeh's (1975) two publics theory helped to understand these fragmentations in reporting practices within a post-colonial African state. For instance, the study's findings highlight that reporting practices within the civic public are inclined towards global practices that are consistent with the expectations of influential supranational institutions such as the UN and the WHO. Consequently, such reporting mechanisms focus on identified performance indicators including mortality rates, morbidity rates and immunisation rates. These indicators are intended to highlight the effectiveness of donor resources and are deemed suitable for reporting back to different donor institutions of a Western origin. Further, most of donor funding appears to be disease-specific in nature to reflect the focus of specific donor agencies. While most of such funding and reporting is based on HIV/AIDS, findings indicate that other donor institutions equally target malaria and tuberculosis. Accordingly, it appears that such reporting practices are aimed at bringing to the fore the accounting and accountability requirements of these institutions. However, a number of such practices are reported to be implemented without the involvement of governments' official structures. Consequently, some of these external accounting and reporting practices are perceived to be unsuitable for meeting the needs of other equally important stakeholders such as local populations (Lassou and Hopper, 2016).

On the other hand, accounting and performance reporting practices within the primordial public appear to be guided by government's health policy. In order to meet the needs of local citizens, this policy requires that health services should be provided in a clean, competent and caring manner as close to the family as possible. While the overarching goal of health service delivery within the civic public remains that of reducing mortality and morbidity rates, performance reporting within the primordial public is aimed at highlighting improvements in general living standards of ordinary people. Government's belief is that such improvements are only attainable through the provision of care to ordinary citizens by constructing health facilities within $5 \mathrm{~km}$ of every residential area including rural communities. In addition to having health facilities of a decent nature, there should be sufficient medical and support staff and drugs in such facilities, and these staff should have a right attitude towards patients. 
It is believed that such an approach will enable government to deliver quality cost effective health services that should ultimately translate into reduced mortality and morbidity rates often reported in the civic public. The delivery of healthcare services in a clean, competent and caring environment is intended to ensure that the needs of local communities are brought to the fore. The Parliamentary Committee plays a critical role in ensuring that the needs of ordinary citizens are taken care of through their representation and oversight roles that often involve field visits to verify performance reports emerging from the civic public. The case in point is the favourable maternal mortality rates reported in the civic public which were immediately dismissed upon undertaking field visits by the Parliamentary Committee. These multiple performances reporting practices highlight the dialectical nature of social values and expectations of citizens belonging to the two publics to reiterate the fact that reporting practices embraced within the civic public may not necessarily be consistent with the expectations of citizens belonging to the primordial public.

In an attempt to close the information gap in the funding, accounting and reporting practices, government and donor institutions have introduced integrated and collaborative reporting structures and practices. These structures and mechanisms are intended to create dialogue between the two parties in order to harmonise and enhance their reporting practices. Accordingly, collaboration between government and donor institutions takes places through diverse structures including the Joint Annual Review, Joint Steering Committee, Joint Executive Committee, Performance Assessment Framework and Annual Consultative Meetings. These structures help in harmonising accounting and reporting practices between stakeholders operating in the civic and primordial publics through joint planning, reporting and monitoring of healthcare services, and coordination in budgeting and the preparation of action plans. The established coordinated arrangements equally help during collaborative health sector policy dialogue and review and promote transparency and accountability while simultaneously attending to the needs of local communities through focusing on social equity. Such collaborative structures and reporting practices are consistent with Ekeh's (1975) thesis of educated African individuals who have to splinter their identities in an attempt to remain legitimate to systems of both publics.

These dynamics in funding, accounting and performance reporting practices entail great implications of a policy nature. Firstly, the multiple reporting practices presented in the above findings mean that the effectiveness of health programmes may be compromised due to the fragmentation in goals between government and international donor institutions. Rather than pooling resources and skills for maximum impact, these practices have the effect of dispersing performance efforts with the consequence of compromising their impact. Secondly, fragmented reporting complicates the work of policy makers in terms of monitoring the progress and impact of such programmes. Within the Zambian context, for instance, donor resources provided through budgetary support are accounted for separately from resources provided through earmarked projects (Ministry of Health and World Bank, 2010). This position arises due to the dominance of supranational institutions that have become a key influence in public sector accounting and governance in many EEs (van Helden and Uddin, 2016). 
However, the dialectical nature of funding, accounting and reporting practices between government and donor agencies has the ultimate consequence of undermining the performance of the health sector in the country due to pulling resources rather than pooling them. Accordingly, the introduction of joint structures and reporting practices is a welcome development that brings the hope of harmonised and improved accounting and reporting that may benefit both individuals and institutions with civic information needs as well as those with primordial needs. Accordingly, the paper contributes to the literature through providing an in-depth account of how accounting and performance reporting requirements of external stakeholders may or may not conform with local practices in an EE context where primordial relations constitute practices of management, budgeting and costing (Wickramasinghe and Hopper, 2005). The study explicates how variations in cultural and value systems between individuals and institutions with civic and primordial information needs call for the adoption of separate sets of accounting and performance reporting practices, mechanisms and structures to meet diverse stakeholder needs.

Consequently, the study makes a theoretical contribution by highlighting the suitability of Ekeh's (1975) post-colonial theory of two publics through depicting the dialectical nature of accounting and performance reporting practices between stakeholders of a Western origin and those of a traditional African origin. Beyond Goddard et al (2016), the study depicts the usefulness of Ekeh's theory in understanding how organisations and institutions operating in pluralistic institutional environments may be better managed. In view of contradictory expectations of accounting and performance reporting requirements between the civic and primordial publics, the study indicates that different practices, mechanisms and structures have to be embraced in order to maintain institutional harmony and relevance to different communities within the health sector. Consistent with Mbembe (2001), actors operating in Zambia's health sector have also learnt to bargain in order to be effective in the pluralistic environment. Due to dynamics taking place in Zambia, this bargaining is taking place through collaborative reporting practices that have emerged and these represent a promising phenomenon for resolving fragmented reporting within the health sector. Accordingly, the blending of institutional pluralism with Ekeh's theory of two publics appears to be a promising theoretical lens that could be of great use for understanding practices in pluralistic institutional environments that characterise EEs.

This study is not without its limitations. In particular, the study relied heavily on actors operating within government institutions whose impartiality may not be guaranteed due to the diplomatic relations with supranational institutions. Accordingly, it is possible that the views expressed by these respondents could be biased towards amplifying either civic or primordial perspectives of accounting and performance reporting. Future research could attempt to draw on focus groups where diverse views could be expressed and possibly challenged by members of the focus group. 


\section{References}

Afolayan, A. (2012), 'Post-colonialism and the two publics in Nigeria: Rethinking the idea of the sceptical public', Ogirisi: A New Journal of African Studies, Vol 9 No. 2, pp. $44-68$.

Alawattage, C., Graham, C. and Wickramasinghe, D. (2015), 'Microaccountability and biopolitics: Microfinance in a Sri Lankan village' Interdisciplinary Perspectives on Accounting Conference, Stockholm, Sweden, pp. 1-48.

Annisette, M. (2004), 'The true nature of the World Bank', Critical Perspectives on Accounting, Vol. 15 No. 3, pp. 303-323.

Ashraf, J., and Uddin, S. (2013), 'A consulting giant; a disgruntled client: a failed attempt to change management controls in a public sector organization', Financial Accountability \& Management, Vol. 29 No. 2, pp. 186-205.

Awio, G. and Northcott, D. (2001), 'Decentralisation and budgeting: The Uganda health sector experience', International Journal of Public Sector Management, Vo. 14 No. 1, pp. 75 -88 .

Awio, G., Lawrence, S. and Northcott, D. (2007), 'Community-led initiatives: reforms for better accountability', Journal of Accounting \& Organizational Change, Vol. 3 No. 3, pp. 209-26.

Blumberg, B., Cooper, D.R., Schindler, P. (2011), 'Business Research Methods', Berkshire, McGraw-Hill Education.

Burns, J., and Scapens, R. W. (2000), 'Conceptualising management accounting change: An institutional framework', Management Accounting Research, Vol. 11 No. 1, pp. 3-25.

Dunn, M.B. and Jones, C. (2010), 'Institutional logics and institutional pluralism: The contestation of care and science logics in Medical Education', Administrative Science Quarterly, Vol. 55, No. 1, pp. 114-149.

Egede, H. (2016), 'African 'social ordering' grundnorms and the development of an African Lex Petrolea’, Denning Law Journal, Vol 28 Special Issue, pp. 138-165.

Ekeh, P.P. (1975), 'Colonialism and the two publics in Africa: A theoretical statement', Comparative Studies in Society and History, Vol. 17, No. 1, pp. 91-112.

Ekeh, P. P. (1994a), 'The public realm and public finance in Africa', In U. Himmelstrand, K. Kinyanjui, \& E. Mburugu (Eds.), African perspectives on development controversies, Dilemmas \& openings (pp. 234-258), London: James Curry.

Ekeh, P. P. (1994b), 'Historical and cross-cultural contexts of civil society in Africa: Civil society, democracy and development in Africa', Proceedings of a workshop for development practitioners, Washington, DC: USAID A-21-A-45, 9-10 June. 
Ekong, S.C. (1988), 'Colonialism: An epochal era - A review of Peter P. Ekeh's writings', Ufahamu: A Journal of African Studies, Vol. 16 No. 1, pp. 1-17.

Everett, J. (2012), 'Corruption in the developing countries: 'thinking about' the role of accounting', In T. Hopper, M. Tsamenyi, S. Uddin, \& D.Wickramasinghe (Eds.), Handbook of accounting and development, Cheltenham: Edward Elgar Publishing.

Goddard, A., and Assad, M.J. (2006), 'Accounting and navigating legitimacy in Tanzanian NGOs', Accounting, Auditing \& Accountability Journal, Vol. 19 No. 3, pp. 377-404.

Goddard, A., Assad, M., Issa, S., Malagila, J., Mkasiwa, T.A. (2016), 'The two publics and institutional theory - A study of public sector accounting in Tanzania', Critical Perspectives on Accounting, Vol. 40, October 2016, pp. 8-25.

Greenwood, R., M. Raynard, F. Kodeih, E. R. Micelotta, and Lounsbury, M. (2011), 'Institutional complexity and organizational responses', The Academy of Management Annals, Vol. 5 No. 1, pp. 317-71.

Hopper, T. (2017), 'Neopatrimonialism, good governance, corruption and accounting in Africa: Idealism vs pragmatism', Journal of Accounting in Emerging Economies, Vol. 7 No. 2, pp. 225-248.

Hopper, T., Tsamenyi, M., Uddin, S., and Wickramasinghe, D. (2009), 'Management accounting in less developed countries: What is known and needs knowing', Accounting, Auditing \& Accountability Journal, Vol. 22 No. 3, pp. 469-514.

Hopper, T., Lassou, P. and Soobaroyen, T. (2017), "Globalisation, accounting and developing countries", Critical Perspectives on Accounting, Vol. 43, March, pp. 125-148, doi: doi.org/10.1016/j.cpa.2016.06.003.

Iyoha, F. O. and Oyerinde, D. (2010), 'Accounting infrastructure and accountability in the management of public expenditure in developing countries: A focus on Nigeria', Critical Perspectives on Accounting, Vol. 21, No.5, pp. 361-73.

Jarzabkowski, P., Matthiesen, J.K., and Van de Ven, A. (2009), 'Doing which work? A practice approach to institutional pluralism.' In Lawrence T., Leca, B. and R. Suddaby. (Eds) Institutional Work: Actors and Agency in Institutional Studies of Organizations, Cambridge, UK: Cambridge University Press.

Jayasinghe, K. and Uddin, S. (2010), 'Continuity and change in WB development discourses and the rhetoric role of accounting', Asia and Pacific Interdisciplinary Research in Accounting Conference Proceedings, July, 2010, Sydney, Australia.

Jayasinghe, K. and Wickramasinghe, D. (2011), 'Power over empowerment: encountering development accounting in a Sri Lankan fishing village', Critical Perspectives on Accounting, Vol. 22 No. 4, pp. 396-414. 
Kraatz, M.S. (2009), "Leadership as institutional work: A bridge to the other side", in Lawrence, T.B., Suddaby, R. and Leca, B. (Eds), Institutional Work: Actors and Agency in Institutional Studies of Organizations, Cambridge University Press, Cambridge, MA.

Kraatz, M.S. and Block, E.S. (2008), 'Organizational implications of institutional pluralism', in Greenwood, R., Oliver, C., Sahlin-Andersson, K. and Suddaby, R. (Eds), The Sage Handbook of Organizational Institutionalism, SAGE Publications, Los Angeles.

Kuruppu, C., Adhikari, P., Gunarathna, V., Ambalangodage, D., Perera, P., Karunarathna, C. (2016), 'Participatory budgeting in a Sri Lankan urban council: A practice of power and domination', Critical Perspectives on Accounting, Vol. 41, December, pp. 1-17.

Lassou, P.J.C. and Hopper, T. (2016), 'Government accounting reform in an ex-French African colony: The political economy of neo-colonialism', Critical Perspectives on Accounting, Vol. 36, April, pp. 39-57.

Lawrence, S., Sharma, U., Nandan, R. (2009), 'Giving institutional theory a critical edge: A study of systems change in a Fijian housing authority', International Journal of Critical Accounting, Vol. 1 No. 4, pp. 390- 405.

Lawuyi, O.B. (2012), 'Sceptical public, public managers and the decline of moral public on Nigeria's public space, An Inaugural Lecture delivered Thursday, 22 March at the University of Ibadan, Ibadan: Ibadan University Press.

Lounsbury, M. (2008), 'Institutional rationality and practice variation: New directions in the institutional analysis of practice', Accounting, Organizations \& Society, Vol. 33 Nos 4-5, pp. 349-361.

Marquis, C. and Lounsbury, M. (2007), 'Vive la resistance: Consolidation and the institutional contingency of professional counter-mobilization in US banking', Academy of Management Journal, Vol. 50 No. 4, pp. 799 - 820.

Mbembe, A. (2001), 'On the Post-colony', (Berkeley: University of California Press).

Mimba, N.P.S.H., van Helden, G.J. and Tillema, S. (2013), 'The design and use of performance information in Indonesian local governments under diverging stakeholder pressures', Public Administration and Development, Vol. 33 No. 1, pp. 15-28.

Ministry of Health (2009), 'Zambia national health accounts 2003 to 2006 - Final Report', Lusaka, Ministry of Health.

Ministry of Health (2011), 'National health strategic plan 2011 - 2015', Lusaka, Ministry of Health.

Ministry of Health (2013), 'National health policy - A nation of healthy and productive people', Lusaka, Ministry of Health. 
Ministry of Health and World Bank (2010), 'Country health status report', Lusaka, Ministry of Health and World Bank African Region Human Development.

Modell, S. (2003), 'Goals versus institutions: The development of performance measurement in the Swedish university sector', Management Accounting Research, Vol. 14 No. 4, pp. 333359.

Modell, S. (2014), 'The societal relevance of management accounting: an introduction to the special issue', Accounting and Business Research, Vol. 44 No. 2, pp. 83-103.

Neu, D. and Ocampo, E. (2007), 'Doing missionary work: the World Bank and the diffusion of financial practices', Critical Perspectives on Accounting, Vol. 18 No. 3, pp. 363-83.

Neu, D., Gomez, E., Graham, C. and Heincke, M. (2006), 'Informing technologies and the World Bank’, Accounting, Organizations \& Society, Vol. 31 No. 7, pp. 635-62.

Neu, D., Rahaman, A.S., Everett, J., Akindayomi, A. (2010), 'The sign value of accounting: IMF structural adjustment programs and African banking reform', Critical Perspectives on Accounting, Vol. 21 No. 5, pp. 402-419.

Nyamori, R. O., Lawrence, S. R., \& Perera, H. B. (2012), 'Revitalising local democracy: a social capital analysis in the context of a New Zealand local authority', Critical Perspectives on Accounting, Vol. 23 Nos. 7-8, pp. 572-594.

Onuoha, B. (2014), 'Publishing postcolonial Africa: Nigeria and Ekeh's two publics a generation after, Social Dynamics, Vol. 40 No. 2, pp. 322-337.

Osaghae, E. (2006), 'Colonialism and civil society in Africa: The perspective of Ekeh's two publics', Voluntas, Vol. 17 No. 3, pp. 233-245.

Pache, A. C. and Santos, F. (2010), 'When worlds collide: The internal dynamics of organizational responses to conflicting institutional demands.' Academy of Management Review, Vol. 35 No. 3, pp. 455-76.

Rahaman, A.S., Gallhofer, S., Haslam, J. and Lawrence, S. (1997), 'Public sector accounting and financial management in LDCs: a critical assessment of the literature', Asian Review of Accounting, Vol. 5 No. 2, pp. 38-65.

Rahaman, A.S., Lawrence, S. and Roper, J. (2004), 'Social and environmental reporting at the VRA: institutionalised legitimacy or legitimation crisis?' Critical Perspectives on Accounting, Vol. 15 No. 1, pp. 35-56.

Rahaman, A.S., Everett, J. and Neu, D., (2007), 'Accounting and the move to privatize water services in Africa', Accounting, Auditing, \& Accountability Journal, Vol. 20 No. 5, pp. 637670 . 
Rahaman, A., Neu, D. and Everett, J. (2010), 'Accounting for social-purpose alliances: confronting the HIV/AIDS pandemic in Africa', Contemporary Accounting Research, Vol. 27 No. 4, pp. 1093-1129.

Republic of Zambia (2013), '2012 joint annual review of the health sector in Zambia', Lusaka, Ministry of Health.

Saasa, O.S. (2010), 'Final report: Budget support - the case of the health sector in Zambia', Premier Consult Limited, Lusaka.

Saravanamuthu, K. (2004), 'Gold-collarism in the academy: the dilemma in transforming bean-counters into knowledge consultants', Critical Perspectives on Accounting, Vol. 15 Nos 4-5, pp. 587-607.

Sharma, U. and Lawrence, S. (2005), 'Public sector reform, global trends versus local needs: The case of a state rental organisation in Fiji', Journal of Accounting and Organisational Change, Vol.1 No. 2, pp.141-164.

Sharma, U. and Lawrence, S. (2009), 'Global remedies for local needs: Corporate governance and public sector reforms in Fiji', Pacific Accounting Review, Vol.21 No. 3, pp. 260-285.

Sharma, U., Lawrence, S., and Lowe, A. (2010), 'Institutional contradiction and management control innovation: A field study of total quality management practices in a privatized telecommunication company', Management Accounting Research, Vol. 21 No.4, pp. 251264.

Sharma, U., Lawrence, S. and Lowe, A. (2014), 'Accountants as institutional entrepreneurs: Changing routines in a telecommunications company', Qualitative Research in Accounting and Management, Vol.11 No. 3, pp. 190-214.

Soobaroyen,T. and Ntim, C.G. (2013), 'Social and environmental accounting as symbolic and substantive means of legitimation: The case of HIV/AIDS reporting in South Africa', Accounting Forum, Vol. 37 No. 2, pp. 92-109.

Soobaroyen, T., Tsamenyi, M. and Supra, H. (2016), "Accounting and governance in Africa: contributions and opportunities for further research", Journal of Accounting in Emerging Economies, Vol. 7 No. 4, pp. 422-427.

Tsamenyi, M., Cullen, J. and Gonzalez, J.M.G. (2006), 'Changes in accounting and financial information systems in a Spanish electricity company: A new institutional theory analysis', Management Accounting Research, Vol.17 No. 4, pp. 409-432.

Uddin, S. and Tsamenyi, M., (2005), 'Public sector reforms and the public interest: a case study of accounting control changes and performance monitoring in a Ghanaian state-owned enterprise', Accounting, Auditing \& Accountability Journal, Vol. 18 No. 5, pp. 648-674. 
Uddin, S., Gumb, B., and Kasumba, S. (2011), 'Trying to make the typologies of the spectacle operational: a literature review and a case study', Accounting, Auditing \& Accountability Journal, Vol. 24 No. 3, pp. 288-314.

van Helden, J. and Ouda, H. (2016), 'Public sector accounting in emerging economies', Critical Perspectives on Accounting, Vol. 40, October, pp. 1-7.

van Helden, J. and Uddin, S. (2016), 'Public sector management accounting in emerging economies: A literature review', Critical Perspectives on Accounting, Vol. 41, December, pp. $34-62$.

Vaivio, J. (2008), 'Qualitative management accounting research: Rationale, pitfalls and potential', Qualitative Research in Accounting and Management, Vol. 5 No. 1, pp. 64 - 86.

Wickramasinghe, D. (2015), 'Getting management accounting off the ground: postcolonial neoliberalism in healthcare budgets', Accounting and Business Research, Vol. 45 No.3, pp. 323-355.

Wickramasinghe, D. and Hopper, T., (2005), 'A cultural political economy of management accounting controls: a case study of a textile mill in a traditional Sinhalese village', Critical Perspectives on Accounting, Vol. 16 No. 4, pp. 473-503.

World Health Organisation (2009), 'WHO country cooperation strategy 2008 - 2013', WHO Regional Office for Africa, Brazaville.

World Health Organisation (2013), 'State of financing in the African region', World Health Organisation, Regional Office for Africa, Johannesburg.

Yang, C. and Modell, M. (2013), 'Power and performance', Accounting, Auditing \& Accountability Journal, Vol. 26 No. 1, pp. 101 - 132.

$\mathrm{Yu}, \mathrm{K}-\mathrm{H}$ (2013), 'Institutionalisation in the context of institutional pluralism; politics as a generative process', Organisation Studies, Vol. 34 No.1, pp. 105-131. 